\title{
Fatty Acids of CLA-enriched Egg Yolks Can Induce Mitochondrial Pathway of Apoptosis in MCF-7 Breast Cancer Cells
}

\author{
ANETA A. KORONOWICZ, MARIOLA DROZDOWSKA, PAULA BANKS, \\ EWELINA PIASNA-SŁUPECKA, DOMINIK DOMAGAŁA and TERESA LESZCZYŃSKA
}

Department of Human Nutrition, Faculty of Food Technology, University of Agriculture in Krakow, Krakow, Poland

\begin{abstract}
Background: Fatty acids from conjugated linoleic acid (CLA)-enriched egg yolk suppressed the viability of the MCF-7 cancer line more effectively than non-enriched egg yolk. Herein we aimed to determine the molecular mechanisms by analysing the expression and activation of proteins involved in cellular stress and apoptosis signaling. Materials and Methods: Forty-eight Isa Brown laying hens (26-week-old) were fed a fortified (0.75\% CLA) or a control diet (0\% CLA) for 4 months. Collected eggs were used to obtain CLA-enriched (EFACLA) or non-enriched (EFA) fatty acid extracts for the treatment of the MCF-7 cancer cell line. Protein levels were analysed by PathScan $®$ Stress and Apoptosis Signalling Antibody Array and western blot method. Results: Treatment with EFA-CLA led to activation of caspase signalling as main effector of apoptosis. It also increased levels of proapoptotic B-cell lymphoma 2 family proteins as well as promoted the release of cytochrome $c$, second mitochondriaderived activator of caspase and mitochondrial serine protease from mitochondria to the cytoplasm. EFA-CLA increased levels of tumour protein 53 and mothers against decapentaplegic homolog 2 tumour suppressors, and activated p38 mitogen-activated protein kinases and stressactivated protein kinase/c-Jun NH2-terminal kinase proteins. Finally, treatment down-regulated anti-apoptotic extracellular signal-regulated protein kinases 1 and 2, RACalpha serine/threonine-protein kinase, heat-shock protein 27 , inhibitor of nuclear factor $k \beta$, transforming growth factor beta-activated kinase 1 and survivin proteins.
\end{abstract}

Correspondence to: Aneta A. Koronowicz, Department of Human Nutrition, University of Agriculture in Krakow, Balicka str. 122, 30149 Krakow, Poland. e-mail: aneta.koronowicz@gmail.com

Key Words: Conjugated linoleic acid, CLA, CLA-enriched egg yolk, CLA preventive antitumour activity, apoptosis, cellular stress response, breast cancer.
Conclusion: Taken together, our results suggest that activation of the mitochondrial apoptotic pathway may be a potential mechanism of EFA-CLA action.

Breast cancer is the most frequently diagnosed cancer among women worldwide and one of the most common causes of death (1). Encouragingly, a study carried out in the USA between 2003 and 2012 showed an overall downward tendency in the death rate. This decrease reflects progress in earlier detection as well as improved treatments (2). However, research in cancer prevention remains insufficient.

Conjugated linoleic acid (CLA) is a term that describes a mixture of positional and geometric isomers of linoleic acid (3). Two main isomers: cis9,trans 11 and trans10,cis 12, have been widely studied and shown to possess significant biological properties $(3,4)$

CLA is commonly available in a synthetic supplement form; however, the ratio of cis9,trans 11 to trans 10 ,cis 12 CLA isomers, most often in equal proportions (1:1), does not reflect those of natural food products. In addition, there are some concerns regarding the safety of certain trans CLA isomers (4). Taking all the above into consideration, it would seem preferable to obtain CLA from naturally-enriched food products. Chicken eggs can be enriched with CLA via feed modification, meeting the criteria of a functional food product $(5,6)$. Supplementation of chicken feed with a mixture of cis9,trans 11 and trans10,cis 12 CLA isomers was found to result in a favourable incorporation into egg yolk of cis 9 ,trans 11 at a $3: 1$ ratio $(6,7)$, similar to that measured for natural, unmodified foods (8).

Our previous studies showed the beneficial effect of a fatty acid extract (EFA) from CLA-enriched eggs in reducing proliferation of breast cancer and melanoma cells $(9,10)$, which was stronger than that for EFA from non-enriched egg yolks. Our recently published Whole Human Genome Microarray analysis of the effect of EFA-CLA vs. EFA on MCF-7 transcriptome profile showed that EFA-CLA promoted the mRNA expression of some tumour suppressors 
and reduced the expression of oncogenes (7). In the current study, we made an attempt to determine further the potential mechanism behind reduced viability of MCF-7 cells after treatment with EFA-CLA.

\section{Materials and Methods}

Production of CLA-enriched egg yolks. Production of CLA-enriched egg yolks was performed at the National Research Institute of Animal Production in Krakow (Poland), as described previously (11). Forty-eight Isa Brown laying hens (26 weeks old) were housed in a controlled room under $14 / 10 \mathrm{~h}$ light/dark cycle, given free access to water and commercial starter diet ('DJ' feed). After a 1week adaptation period, an equal number of hens was randomly allocated to the control or experimental group for 4 months of the experiment. Diets were calculated to provide $2700 \mathrm{kcal} / \mathrm{kg}$ and $17 \%$ crude protein. The $0.75 \%$ dietary CLA (Tonalin FFA 80; BASF Company, Ludwigshafen, Rhineland-Palatinate, Germany) contained 80\% CLA in 50:50 ratio for cis9,trans11 and trans10,cis12 isomers. Eggs were collected daily for 10 weeks and stored at $4{ }^{\circ} \mathrm{C}$. Yolks were separated from albumen, homogenized and frozen at $-20^{\circ} \mathrm{C}$. Samples were then lyophilized and again stored at $-20^{\circ} \mathrm{C}$ until further use or analysis.

Fatty acid extraction and analysis of fatty acid methyl esters (FAME). Lipids from control and CLA-enriched yolks were extracted, derivitised to FAME and analysed by gas chromatography-mass spectrometry as described previously (8). For cell treatment, lipid extracts were subjected to basic hydrolysis $(0.5$ $\mathrm{M} \mathrm{KOH}$ at $60^{\circ} \mathrm{C}$ for $15 \mathrm{~min}$ ) and then extracted with hexane. The free fatty acids were then dissolved in ethanol (Avantor Performance Materials Poland, Gliwice, Poland) at a stock concentration of 1 $\mathrm{g} / \mathrm{ml}$ and stored under nitrogen at $-20^{\circ} \mathrm{C}$.

Cell culture. The human breast adenocarcinoma cell line MCF-7 (ATCC ${ }^{\circledR}$ HTB22TM) was purchased from the American Type Culture Collections (ATCC, Manassas, VA, USA). Cells were cultured in appropriate medium (Sigma-Aldrich, St Louis, MO, USA) according to the ATCC ${ }^{\circledR}$ protocol.

Cell treatment. MCF-7 cells were seeded on 96-well plates at $8 \times 10^{3}$ cells per well, 12 -well plates at $9 \times 10^{4}$ cells per well, or 6-well plates at $2 \times 10^{5}$ cells per well. Twenty-four hours after seeding, growth medium was replaced with fresh medium containing: a) $0.5 \mathrm{mg} / \mathrm{ml}$ EFA-CLA), b) $0.5 \mathrm{mg} / \mathrm{ml}$ EFA from non-enriched egg yolks, or c) ethanol as solvent at final concentration of $0.1 \%$ as negative control (NC). Cells were treated for $48 \mathrm{~h}$. Staurosporine was used as a positive control (Sigma-Aldrich) at a final concentration of $1.5 \mu \mathrm{M}$. Each treatment included three biological and three technical replicates.

Cytotoxicity assay. Cell viability was determined by the Crystal Violet Assay (Sigma-Aldrich and Cytotoxicity Detection Kit LDH (Roche Poland, Warszawa, Poland) according to the manufacturers' protocols.

Plasma membrane alteration in early apoptosis. Annexin-V-FLUOS Staining Kit (Roche) was used according to the manufacturer's protocol to detect induction of MCF-7 cell apoptosis after treatment with EFA-CLA and EFA.

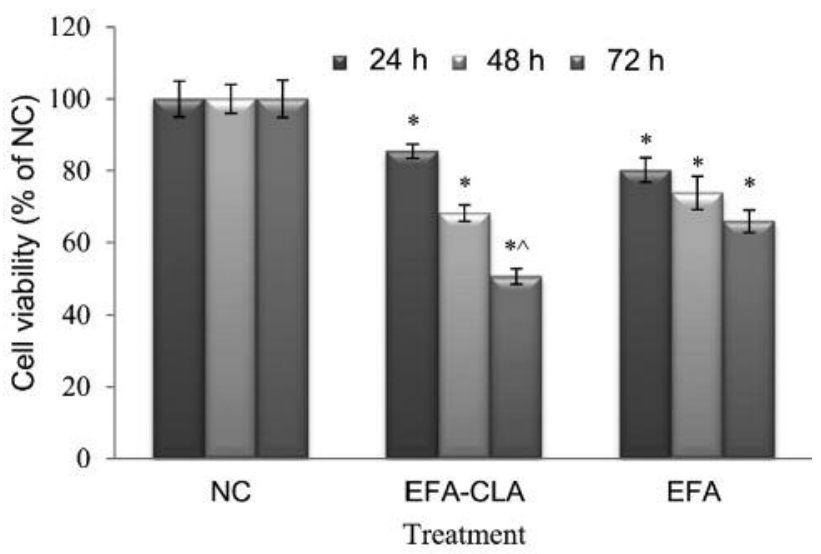

Figure 1. Effect of fatty acid extract from conjugated linoleic acidenriched egg yolks (EFA-CLA) on MCF-7 cell viability. Values are expressed as means $\pm S D(n=8)$, standardized to the solvent-untreated control (NC) set as 100\%. Statistical significance was based on t-test. Significantly different at $p<0.01 \mathrm{vs} .{ }^{*} N C$ and ${ }^{\wedge}$ non-enriched egg yolk (EFA). Fatty acid concentration: $0.5 \mathrm{mg} / \mathrm{ml}$.

Stress and apoptosis signaling assay. Cell extracts were prepared and analyzed using PathScan ${ }^{\circledR}$ Stress and Apoptosis Signaling Antibody Array Kit (Chemiluminescent Readout; Cell Signalling Technology, Danvers, MA, USA) as described previously (13).

Western blot assay. Whole-cell and cellular fraction lysis were carried out using Cell Lysis Buffer and Cell Fractionation Kit (Cell Signaling Technology) with the addition of Protease Inhibitor Cocktail (BioShop, Mainway, Burlington, ON, Canada) according to the manufacturers' protocols. Total protein was quantified with Pierce BCA $^{\mathrm{TM}}$ Protein Assay Kit (Thermo Fisher Scientific, Waltham MA, USA). Each western blot followed a similar procedure. Protein extract was separated on a polyacrylamide gel and transferred to a nitrocellulose filter (Bio-Rad, Hercules, CA, USA) by wet-electroblotting. Subsequently, the immobilized proteins were incubated with appropriate primary antibody to: p53 (\#2527), cytochrome $c$ (\#11940), BH3-interacting domain death agonist (BID) (\#2002), BCL2associated X, apoptosis regulator (BAX) (\#5023), BCL2-associated agonist of cell death (BAD) (\#9239), second mitochondria-derived activator of caspase (SMAC/DIABLO) (\#2954), mitochondrial serine protease (HTRA2/OMI) (\#9745), p53 up-regulated modulator of apoptosis (PUMA) (\#4976), caspase-9 (\#9502), and glyceraldehyde3-phosphate dehydrogenase GAPDH (\#5174) as a reference protein (Cell Signaling Technology, Danvers, MA, USA). Finally, appropriate secondary antibody conjugated with horseradish peroxidase (\#7074; Cell Signaling Technology) was applied. Detection was executed by chemiluminescence, using Clarity ${ }^{\mathrm{TM}}$ Western ECL Substrate (Bio-Rad Western blot stripping buffer (Thermo Fisher Scientific) was used to remove the antibodies from the membrane. Densitometric analysis was performed using ImageJ.

Statistical analysis. All assays were performed in at least three independent experiments and measured in triplicate. The ShapiroWilk's test was applied to assess normality of distribution. An independent samples $t$-test was applied to compare unpaired means 


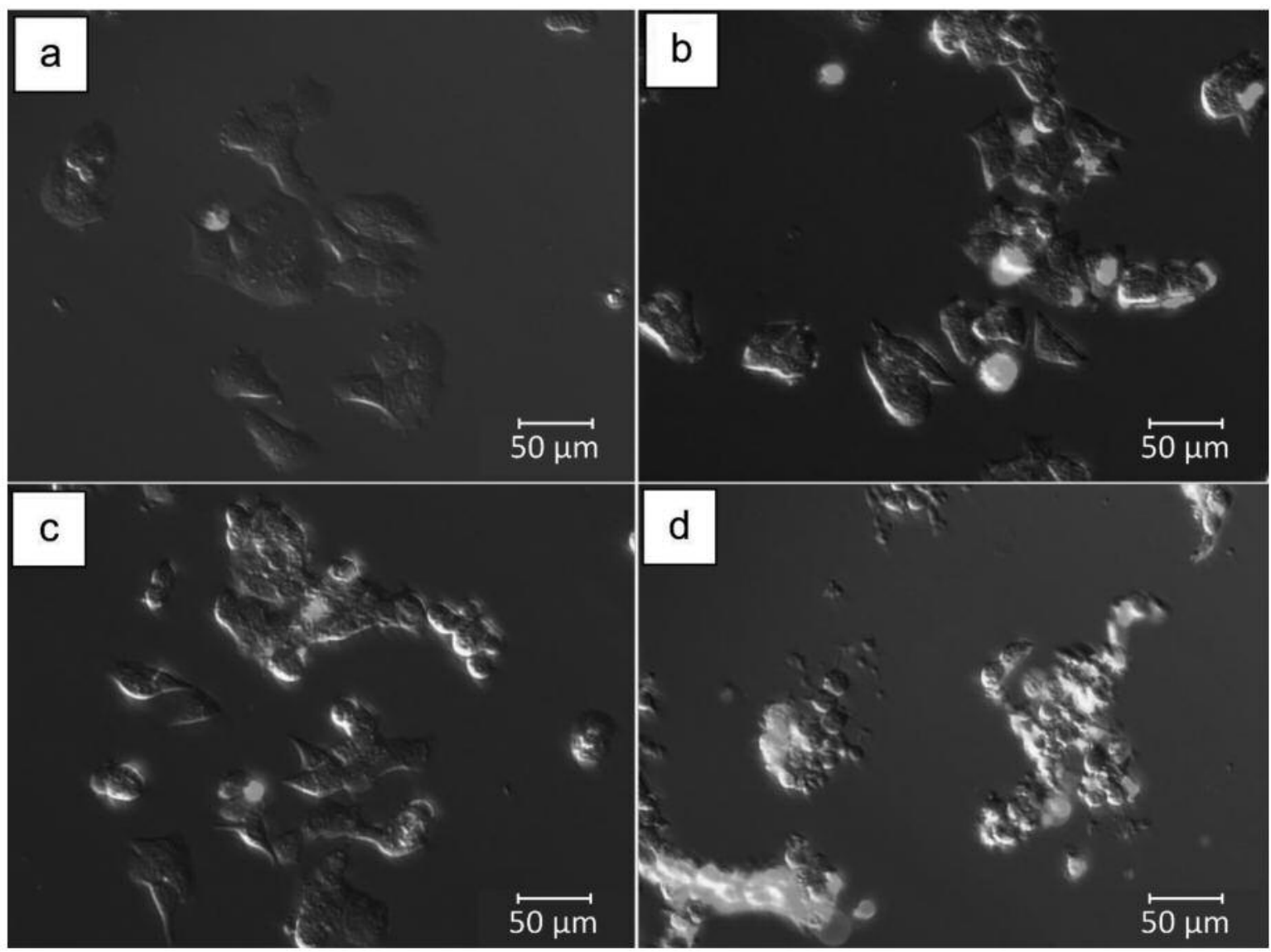

Figure 2. Effect of fatty acid extract from conjugated linoleic acid-enriched egg yolks (EFA-CLA) on early events of apoptosis in MCF-7 cells. $M C F-7$ cells were untreated (a) or treated with EFA-CLA (b), non-enriched egg yolk (EFA) (c), or $1.5 \mu M$ staurosporine as positive control (d) for 72 h. Cells were stained with Annexin V-FLUOS kit. The cell cultures were subsequently analysed using a Zeiss Axio Observer Z1 fluorescence microscope. Annexin V-FLUOS-positive cells are stained green and represent apoptotic cells.

between two groups and differences with values of $p<0.05$ were considered statistically significant. All analyses were performed using Statistica ver.12 (StatSoft, Tulsa, OK, USA).

\section{Results}

Analysis of cell viability. Both treatments with EFA-CLA and EFA reduced the viability of MCF-7 breast cancer cells compared to the NC. At $72 \mathrm{~h}$ post treatment, cell viability in the EFA-CLA-treated group had decreased by $50 \%$ and that of the group treated with EFA by $35 \%$ (Figure 1).

Plasma membrane alteration in early apoptosis. Results from the Annexin-V-FLUOS assay indicated early apoptosis stage for both treatment groups; however, this was more pronounced for the EFA-CLA treated group (Figure 2).

Expression of stress and apoptosis signalling proteins. The results of the PathScan ${ }^{\circledR}$ Stress and Apoptosis Signalling Antibody Array analysis are presented in Figure 3.
EFA-CLA significantly reduced the level of the pro-survival phosphorylated form of P44/42 mitogen-activated protein kinases (MAPK) [extracellular signal-regulated protein kinases 1 and $2($ ERK $1 / 2)]$ to $48 \%$ that of $\mathrm{NC}(p<0.05)$. In addition, this effect was also statistically significant compared to that of EFA ( $94 \%$ of NC; $p<0.005$ ) (Figure 3 ). Similar results were found for the phosphorylated form of heat-shock protein 27 (HSP27). Significant decrease in protein expression was measured for both EFA-CLA- and EFA-treated cells (35\% and $20 \%$ of NC, respectively; $p<0.01$ ) (Figure 3). Serine/threonineprotein kinase (AKT1) and survivin expression also showed a tendency to decrease, but not statistically significantly, in EFACLA-treated cells (81\% and $94 \%$ of NC, respectively) (Figure 3). Similarly, there was a negligible decrease in the level of the active form of transforming growth factor beta-activated kinase 1 (TAK1) in EFA-CLA- and EFA-treated cells (95\% and $75 \%$ of NC, respectively) (Figure 3).

EFA-CLA treatment resulted in a significant increase in the level of the phosphorylated form of BAD protein 


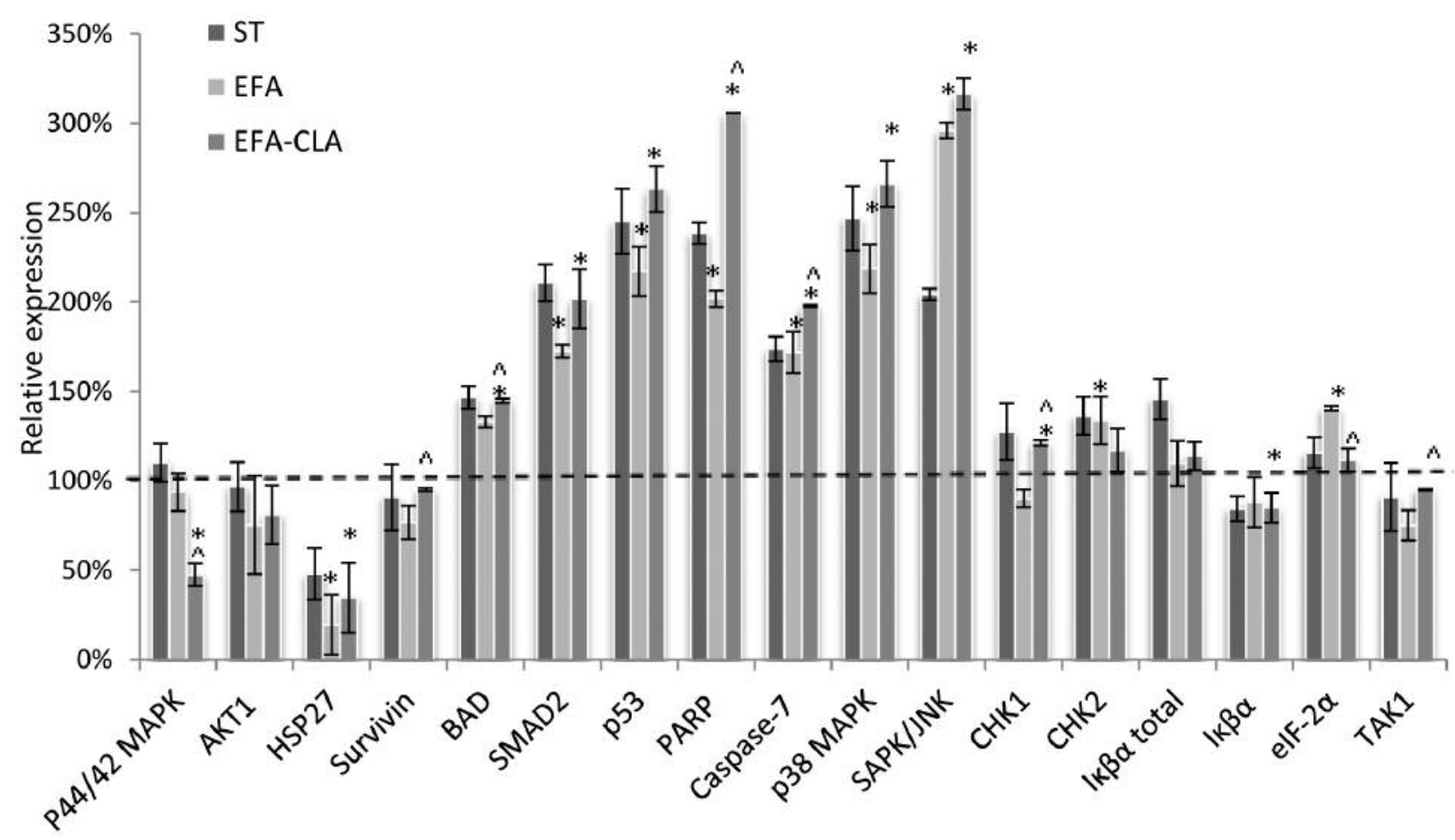

Figure 3. Expression of stress and apoptosis signalling proteins in MCF-7 cells. MCF-7 cells were treated for $48 \mathrm{~h}$ with $0.5 \mathrm{mg} / \mathrm{ml}$ fatty acid extract from conjugated linoleic acid-enriched egg yolks (EFA-CLA), or from control egg yolks (EFA), or with 1.5 uM staurosporine (ST) as positive control. Cell extracts were prepared and analysed using the PathScan ${ }^{\circledR}$ Stress and Apoptosis Signaling Antibody Array Kit (Cell Signaling Technology, Danvers, MA, USA). Densitometric analysis was performed using ImageJ. Results are shown as the mean $\pm S D$ normalized to the internal reference protein ( $\alpha$-tubulin). Expression of the solvent-treated negative control (NC) was set as 100\%. Statistical significance of EFA-CLA was based on $t$ test. Significantly different at $p<0.01 \mathrm{vs}$. *NC and ${ }^{\wedge} E F A$. P44/42 MAPK: Extracellular signal-regulated protein kinases 1 and 2 (ERK1/ 2); AKT1: serine/threonine-protein kinase; HSP27: heat-shock protein 27; BAD: BCL2-associated agonist of cell death; SMAD2: mothers against decapentaplegic homolog 2; p53: tumour protein 53; PARP: poly(ADP)-ribose] polymerase; SAPK/JNK: stress-activated protein kinase/c-Jun NH2terminal kinase; p38MAPK: 38 mitogen-activated protein kinases; CHK1: checkpoint kinase 1; CHK2: checkpoint kinase 2; Ik $\beta \alpha$ : inhibitor of nuclear factor $k \beta$; eIF-2 $\alpha$ : eukaryotic translation initiation factor 2 subunit 1; TAK1: transforming growth factor beta-activated kinase 1.

compared to NC $(145 \%$ of NC; $p<0.05)$ and to EFA-treated cells $(p<0.01)$. Similar results were found for tumour suppressors phosphorylated $\mathrm{p} 53$ and mothers against decapentaplegic homolog 2 (SMAD2) (263\% and 202\% of NC, respectively; $p<0.01$ ) (Figure 3 ). EFA had a similarly significant effect on p53 and SMAD2 (217\% and 173\% of $\mathrm{NC}$, respectively). In addition, there was an increase in the cleaved form of poly (ADP-ribose) polymerase (PARP) after both EFA-CLA and EFA treatment (306\% and $202 \%$ of NC, respectively; $p<0.001)$, which was significantly higher for EFA-CLA $(p<0.005)$ (Figure 3). EFA-CLA had a significant effect on caspase-7 cleavage $(198 \%$ of NC; $p<0.001)$ as well as on p38 MAPK $(266 \%$ of $\mathrm{NC} ; p<0.01)$ and phosphorylation of stress-activated protein kinase (SAPK)/cJun NH2-terminal kinase (JNK) MAPKs (316\% of NC; $p<0.01$ ) (Figure 3).

Results for EFA-CLA also showed a significant increase in phosphorylated checkpoint kinase 1 (CHK1) level (121\% of NC; $p<0.05)$ but a statistically insignificant increase for
CHK2 (117\% of NC) (Figure 3). For inhibitor of nuclear factor $\kappa \beta(\operatorname{I\kappa } \beta \alpha)$, no changes were found in total protein levels for cells treated with either EFA-CLA or EFA. However, EFA-CLA led to a significant decrease in the level of the phosphorylated form of Iк $\beta \alpha$ ( $85 \%$ of NC; $p<0.05)$ (Figure 3). Our results showed no effect on total eukaryotic translation initiation factor 2 subunit 1 (eIF-2 $\alpha$ ) expression; however, they showed a slight increase in the phosphorylated protein form in cells treated with EFA ( $112 \%$ of NC; $p<0.05)$ (Figure 3).

Western blot analysis of protein levels in cell lysate. Western blot results showed the effect of EFA-CLA treatment on proteins known to be involved in mitochondrial-induced apoptosis. P53 and cytochrome $c$ were found at significantly higher levels in whole-cell lysate from cells treated with EFA-CLA (Figures 4 and 5). Further analysis of membrane and cytoplasmic fractions showed significant accumulation of cytochrome $c$ in the cytoplasm at the expense of the 


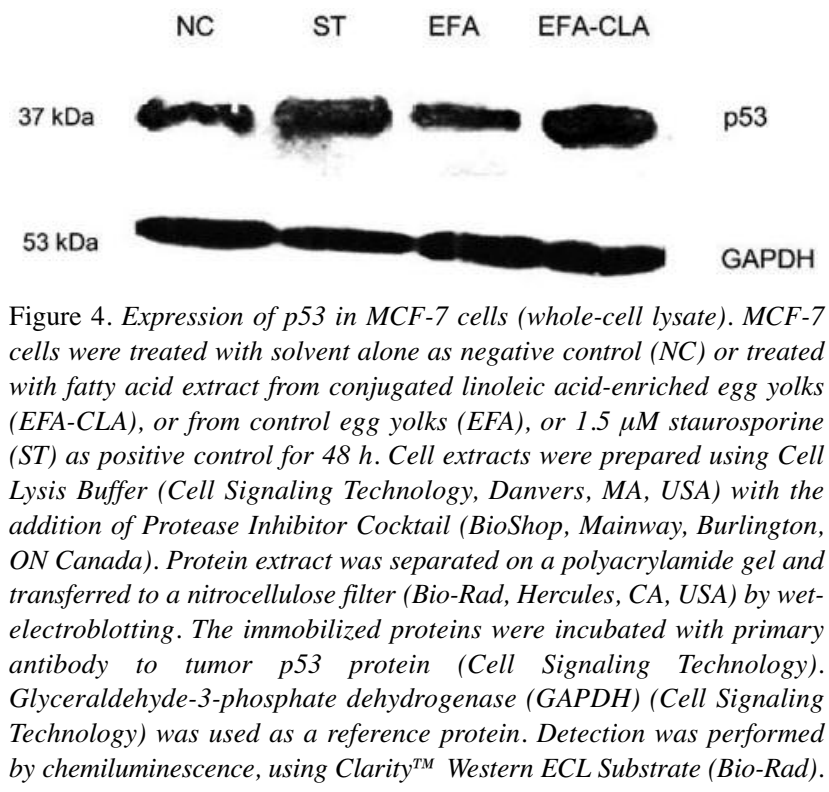

membranous fraction (Figure 5). BAD protein was shown to be accumulated in the membranous fraction (Figure 6) together with other pro-apoptotic proteins from the BCL2 family, notably BID, BAX and PUMA (Figure 6). Our results also showed an increased level in whole-cell lysate of SMAC/DIABLO and HTRA2/OMI proteins, which promote caspase activity (Figure 5). Finally, protein levels of caspase- 9 were measured due to being directly related to the mitochondrial pathway. Our results showed the presence of the cleaved form of caspase-9 (Figure 7).

\section{Discussion}

In the current study, we made an attempt to determine potential mechanisms behind reduced viability of MCF-7 cells after treatment with EFA-CLA (Figure 1).

Cells integrate multiple signals from a variety of sources before following either pro- or anti-apoptotic pathways (Figure 8). To examine whether apoptosis was the primary cause of cell death, we analysed the levels of proteins associated with apoptotic events. Furthermore, we verified the effect of EFA-CLA on selected proteins involved in cellular stress signalling with respect to their integration into apoptosis induction.

One of the earliest stages of apoptosis includes changes on the cell surface. Phosphatidylserine is an important phospholipid membrane component present in the inner side of the plasma membrane. During apoptotic events, phosphatidylserine is translocated to the surface where it acts as a signal for macrophages to engulf apoptotic cells $(14,15)$. Annexin V, a calcium-dependent phospholipid-binding protein,

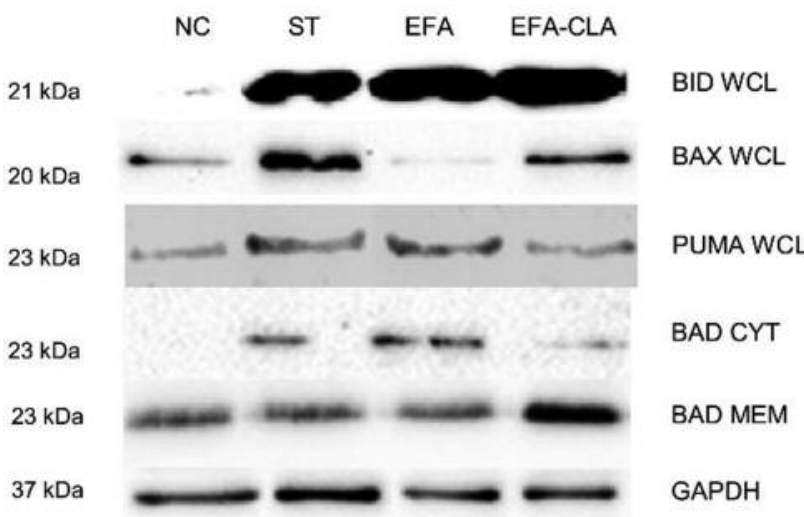

Figure 5. Expression of BH3-interacting domain death agonist (BID), apoptosis regulator $B A X(B A X), B C L 2$-associated agonist of cell death (BAD) and p53 up-regulated modulator of apoptosis (PUMA) proteins in MCF-7 cells. MCF-7 cells were treated with solvent alone as a negative control (NC) or treated with fatty acid extract from conjugated linoleic acid-enriched egg yolks (EFA-CLA), or from control egg yolks (EFA), or $1.5 \mu \mathrm{M}$ staurosporine (ST) as positive control for $48 \mathrm{~h}$. Cell extracts were prepared using Cell Lysis Buffer (Cell Signaling Technology, Danvers, MA, USA) with the addition of Protease Inhibitor Cocktail (BioShop, Mainway, Burlington, ON Canada). Protein extract was separated on a polyacrylamide gel and transferred to a nitrocellulose filter (Bio-Rad, Hercules, CA, USA) by wetelectroblotting. The immobilized proteins were incubated with primary antibodies to BID, BAX, BAD and PUMA (Cell Signaling Technology, Danvers, MA, USA). Glyceraldehyde-3-phosphate dehydrogenase (GAPDH) (Cell Signaling Technology) was used as a reference protein. Detection was performed by chemiluminescence, using Clarity ${ }^{T M}$ Western ECL Substrate (Bio-Rad). WCL, Whole-cell lysate; CYT, cytoplasmic cellular fraction; MEM, membranous cellular fraction.

has high affinity for phosphatidylserine, and its fluorochromelabelled form is used in detection of apoptotic changes using assay kits. Our results clearly showed the induction of apoptosis after treatment with both fatty acid extracts, with the effect of EFA-CLA being more pronounced (Figure 2).

To further verify our initial findings, western blot was carried out targeting proteins associated with apoptotic events (Figures 3-7). Our results for EFA-CLA-treated MCF7 cells showed an increased accumulation of p53 protein in cell lysates, compared to NC and EFA-treated cells (Figures 3 and 4). Accumulation of p53 protein in cancer cells has been associated with suppressed growth and division (16). As a transcription factor, p53 is responsible, among others, for the expression of mitochondrial-induced pro-apoptotic proteins, i.e. BAX, BID, BAD and PUMA (17-19). Indeed, our results confirmed that EFA-CLA, simultaneously with increasing p53, increased the levels of BAX, BID, BAD and PUMA proteins (Figure 3,6).

BAX, BID, BAD and PUMA, among many others, belong to the BCL2 family. Activity and interdependencies of BCL2 family proteins play a pivotal role in the regulation of cell death 


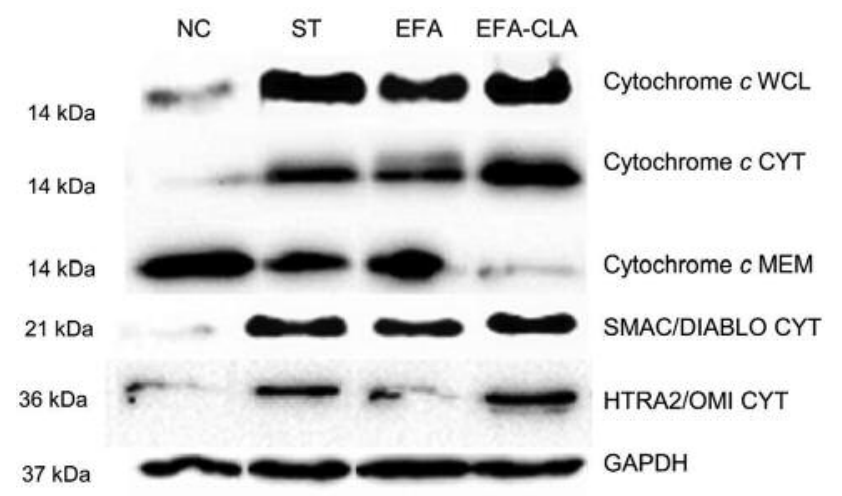

Figure 6. Expression of cytochrome c, second mitochondria-derived activator of caspase/direct inhibitor of apoptosis-binding protein with low pI (SMAC/DIABLO) and mitochondrial serine protease (HTRA2/OMI) in MCF-7 cells. MCF-7 cells were treated with solvent alone as a negative control (NC) or treated with fatty acid extract from conjugated linoleic acid-enriched egg yolks (EFA-CLA), or from control egg yolks (EFA) or $1.5 \mu \mathrm{M}$ staurosporine (ST) as positive control for 48 h. Cell extracts were prepared using Cell Lysis Buffer (Cell Signaling Technology, Danvers, MA, USA) with the addition of Protease Inhibitor Cocktail (BioShop, Mainway, Burlington, ON Canada). Protein extract was separated on a polyacrylamide gel and transferred to a nitrocellulose filter (Bio Bio-Rad, Hercules, CA, USA) by wetelectroblotting. The immobilized proteins were incubated with primary antibodies to cytochrome c, SMAC/DIABLO and HTRA2/OMI (Cell Signaling Technology). Glyceraldehyde-3-phosphate dehydrogenase $(G A P D H)$ (Cell Signaling Technology) was used as a reference protein. Detection was performed by chemiluminescence, using Clarity ${ }^{T M}$ Western ECL Substrate (Bio-Rad). WCL, Whole-cell lysate; CYT, cytoplasmic cellular fraction; MEM, membranous cellular fraction.

(20). Activation of PUMA indicates that it plays a critical role in the p53 tumour-suppressor pathway. It was shown that disruption of the PUMA gene reduced p53-mediated apoptosis and tumour suppression (21). In addition, Puma-knockout mice showed abnormal response to apoptotic stimuli (22). Our results also showed the accumulation of $\mathrm{BAD}$ protein in the membranous fraction (Figure 6). Phosphorylated BAD normally remains sequestered by 14-3-3 in the cytosol and once dephosphorylated, it will be translocated to the mitochondrial membrane to release cytochrome $c$ (23). Thus, our results suggest the accumulation of pro-apoptotic, non-phosphorylated form of BAD. Interestingly, at the same time our data from the Stress and Apoptosis Signalling Array showed an increased level of the phosphorylated form of BAD in the cytosol (Figure 3 ). Fernando et al. showed that phosphorylated BAD exerted cell cycle-inhibitory effects by targeting cyclin D1 (24). Thus, the presence of both forms suggests that BAD may act via both pro-apoptotic and antiproliferative mechanisms to prevent cancer cell growth (Figure 8).

Our results showed an increased level of cytochrome $c$ after treatment of MCF-7 cells with EFA-CLA (Figure 5), as well as its translocation from the membrane to the cytosol (Figure

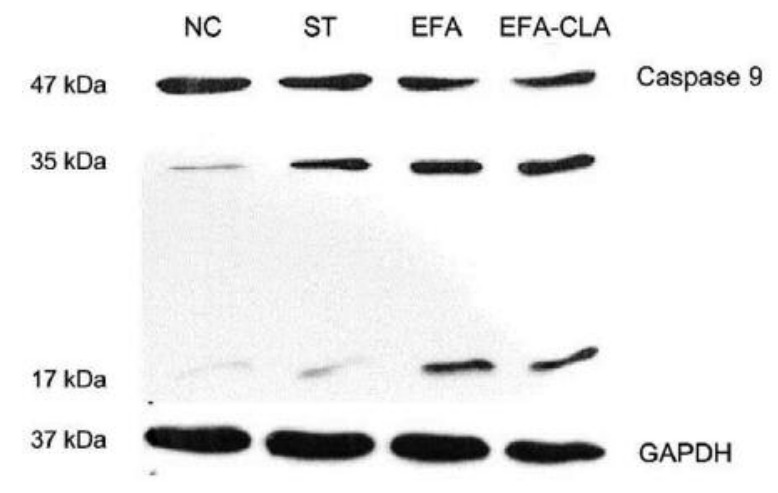

Figure 7. Expression of caspase- 9 in MCF-7 cells (whole-cell lysates). MCF-7 cells were treated with solvent alone as negative control (NC) or treated with fatty acid extract from conjugated linoleic acid-enriched egg yolks (EFA-CLA), or from control egg yolks (EFA), or $1.5 \mu \mathrm{M}$ staurosporine $(S T)$ as positive control for $48 \mathrm{~h}$. Cell extracts were prepared using Cell Lysis Buffer (Cell Signaling Technology, Danvers, MA, USA) with the addition of Protease Inhibitor Cocktail (BioShop, Mainway, Burlington, ON, Canada). Protein extract was separated on a polyacrylamide gel and transferred to a nitrocellulose filter (Bio-Rad, Hercules, CA, USA) by wet-electroblotting. The immobilized proteins were incubated with primary antibodies to caspase-9 (Cell Signaling Technology). Glyceraldehyde-3-phosphate dehydrogenase (GAPDH) (Cell Signaling Technology) was used as a reference protein. Detection was performed by chemiluminescence, using Clarity ${ }^{T M}$ Western ECL Substrate (Bio-Rad).

5). In addition, we found a similar relationship for SMAC/DIABLO and HTRA2/OMI; specifically, their increased accumulation in the cytosolic fraction (Figure 5). Interestingly, for all our results, the effect was stronger for EFA-CLA compared with EFA (Figures 4-7). Pro-apoptotic BCL2 family members (including BID, BAX, BAD, BCL2like protein 11 (BIM), and PUMA] are normally localised in the cytoplasm; however, during apoptosis induction, they can be activated and translocated to the outer mitochondrial membrane. As a result, they participate in the release of cytochrome c, as well as SMAC/DIABLO and HTRA2/OMI proteins from the mitochondria to the cytoplasm, consequently activating caspases. To our knowledge, this is the first study supporting this mechanism for the action of EFA-CLA.

Our results also showed a decrease in the level of phosphorylated HSP27 as well as of survivin (Figure 3). HSP27 is a mediator of cell stress that confers resistance to adverse environmental conditions. It inhibits the release of cytochrome $c$ from the mitochondria and increases the expression of AKT (25) (Figure 8). Signalling Array results also showed that EFA-CLA reduced the levels of phosphorylated AKT1 and ERK1/2 MAPKs (Figure 3). ERK1/2 MAP and AKT kinases are major signalling nodes that primarily transmit growth and proliferation signals (26, 27). In addition, AKT phosphorylates pro-apoptotic BAD 


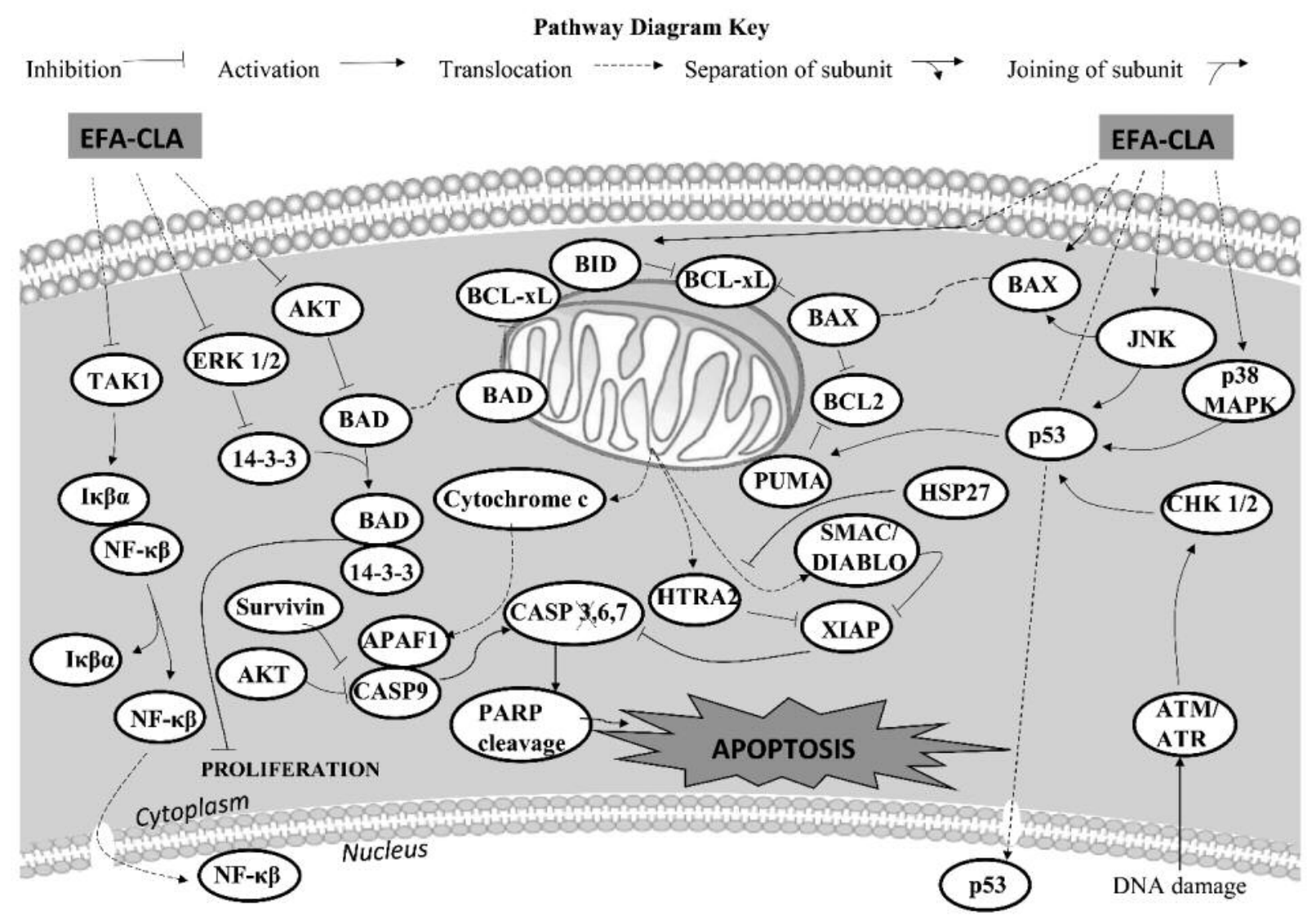

Figure 8. Mechanism of fatty acid extract from conjugated linoleic acid-enriched egg yolks (EFA-CLA)-induced apoptosis in MCF-7 breast cancer cells [modified from (13)].

protein at Ser136 and inhibits its ability to induce apoptosis $(23,28)$. Survivin, on the other hand, binds and inhibits caspase-3 and promotes cell division (29-32) (Figure 8).

Our results also showed a significantly increased level of phosphorylated SMAD2 (Figure 3), which is a key mediator of transforming growth factor beta 1 (TGF $\beta 1$ ) signalling. Available literature suggests that TGF $\beta 1$ induces apoptosis via the mitochondrial pathway, including activation and translocation of BAX and BAD into mitochondrial membranes, release of cytochrome $\mathrm{c}$, as well as activation of caspase- 3 and PARP (33). Further research on pro-apoptotic effects of TGF $\beta 1$ in BME-UV1 bovine cancer cell line showed the activation of classic SMAD signalling pathway. Specifically, TGF $\beta 1$ stimulation led to SMAD2 phosphorylation of Ser465/467 followed by SMAD2 translocation to the nucleus, which initiated transcription of specific genes (34).

Activation of p38 MAPK and SAPK/JNK MAPKs (Figure 3) occurs during dual phosphorylation mechanism in response to cell stressors. The functional consequence of their activation is regulation of inflammatory response, cell-cycle arrest and cellular stress-induced apoptosis (Figure 8). It has been shown that SAPK/JNK and p38 contribute to apoptotic signal transduction in response to various stressors $(35,36)$. The literature indicates that SAPK/JNK can contribute to the activation of both c-JUN/AP1 external apoptosis pathway, as well as the mitochondrial apoptosis pathway discussed here. Both mechanisms may act independently or co-operate with one another to induce cell death (37).

CHK1 and CHK2 kinases (Figure 3) play an important role in DNA damage checkpoint control. They also affect the post-translation modifications of p53 protein (Figure 8). In response to stressors (e.g. DNA damage), ATM serine/threonine kinase (ATM) and ATR serine/threonine kinase (ATR) kinases together with CHK1 and CHK2 phosphorylate p53 on Ser15 and Ser20. This leads to inhibition of p53 interaction with MDM2 and inhibition of p53 ubiquitination. As a result, the level of tumoursuppressor protein p53 increases $(38,39)$. Our results showed that treatment with EFA-CLA increased the expression of kinases CHK1 (statistically significant) and CHK2 (statistically insignificant) (Figure 3), supporting the hypothesis of pro-apoptotic activity of EFA-CLA. 
Iк $\beta \alpha$ forms a complex with nuclear factor kappa B (NF-к $\beta$ ) transcription factor, inhibiting NF- $\mathrm{\kappa} \beta$ activity associated with the up-regulation of anti-apoptotic gene expression (Figure 8). On the other hand, phosphorylation of Iк $\beta \alpha$ results in NF-k $\beta$ release and its translocation to the nucleus, where it can function as a transcription factor (39). Although there were no significant changes in the level of total IK $\beta \alpha$, our results showed a significant decrease in the phosphorylated form of Ik $\beta \alpha$ in EFACLA-treated cells (Figure 3). In addition, our results showed a decrease in the expression of the active TAK1 form. Activated TAK1 promotes phosphorylation of IK $\beta \alpha$ protein and mitogenactivated protein kinase kinase 4 (MKK4), MKK3/6 and mitogen-activated protein kinase kinase kinase 14 (40). Taken together, EFA-CLA treatment seems to target the activation of NF- $\kappa \beta$ via reducing the level of phosphorylated Iк $\beta \alpha$, again supporting the hypothesis of its pro-apoptotic properties.

Cytochrome $c$, SMAC/DIABLO and HTRA2/OMI proteins activate the caspase-dependent mitochondrial pathway (42-45) (Figure 8). In the cytoplasm, cytochrome $c$ interacts with apoptotic peptidase-activating factor 1 protein and pro-caspase-9 to form a so-called apoptosome (46). Once formed, the apoptosome can activate inactive procaspase-9 (47), followed by activation of effector caspases, including caspase-3/7 $(37,48)$. Interestingly, our results for EFA-CLA showed a slight decrease in the level of procaspase-9 (Figure 7) and an increase in the level of its active form (Figure 7). This effect was also observed for EFA, however, less pronounced (Figure 7). SMAC/DIABLO and HTRA2/OMI play a role in promoting apoptosis by inhibiting the activity of IAP (IAP binding protein), an inhibitor of caspase-3 (49). Although our results clearly indicate activation of apoptotic events, we were unable to detect the presence of caspase-3, as the MCF-7 cell line lacks caspase- 3 owing to a functional deletion in the CASP 3 gene (50). However, some studies suggest that apoptosis can occur without the activation of caspase-3 and via the activation of caspase-7 $(51,52)$, or even via other proteases as cell death executioners $(53,54)$. Those hypotheses find confirmation in our results as treatment with EFA-CLA showed increased levels of activated caspase-7 as well as the cleaved form of PARP (Figure 3).

Finally, PARP is a DNA repair and apoptosis enzyme that is inactivated when cleaved at Asp214 by caspase-3 or caspase7 (55). Thus, finally we verified the induction of apoptosis by EFA-CLA. The results shown here indicate that the EFA-CLA fatty acids studied by us induce the mitochondrial apoptosis pathway. Although in the literature there is information on the induction of apoptosis in relation to synthetic CLA isomers (56, 57), we present the first report of induction of apoptosis due to EFA from a CLA-enriched product (Figure 8).

The American Dietetic Association recognizes beef (as well as lamb, turkey, and dairy product) as a functional food due to its CLA content (58). In this context, our study strengthens the position of CLA-enriched eggs as a functional product. We admit that our results are based on an in vitro model which requires further verification in vivo; however, we showed for the first time the potential molecular mechanism behind inhibition of growth of MCF-7 cancer cells treated with extract from CLA-enriched yolks via mitochondrial-induced apoptosis (Figure 8). The signaling pathway proposed here might also explain reduced viability of cancer cells by other CLA-enriched products. It would be beneficial to test this hypothesis on other cancer cell lines.

\section{Conclusion}

In conclusion, our results, for the first time, show the complete mechanism for the effect of EFA-CLA on the MCF-7 breast cancer cell line: the activation of intrinsic, mitochondrial apoptotic pathway, supported by the JNK signaling pathway. Our conclusions are strengthened by the down-regulation of pro-survival proteins by EFA-CLA treatment. Taken together, our findings support the hypothesis that CLA-enriched eggs might be an easily available functional food product with a potential chemopreventative activity.

\section{Funding}

This work was supported by the Polish National Science Center under Grant (number 2011/03/B/NZ9/01423) "Conjugated linoleic acid (CLA)-induced transcriptional activation of PPAR-an investigation of molecular mechanisms of putative anticancer action of fatty acids of CLA enriched egg yolks".

\section{Disclosure Statement}

The Authors report no conflict of interest in regard to this study.

\section{Acknowledgements}

The Authors thank Dr Małgorzata Pierzchalska who allowed us to use the fluorescence microscope and provided us with technical assistance.

\section{References}

1 Ferlay J, Soerjomataram I, Ervik M, Dikshit R, Eser S, Mathers C, Rebelo M, Parkin DM, Forman D and Bray F: GLOBOCAN 2012 v1 .0, Cancer Incidence and Mortality Worldwide: IARC CancerBase No. 11 [Internet]. Lyon, France: International Agency for Research on Cancer, 2013. http://globocan.iarc.fr Accessed 18 July 2016.

2 American Cancer Society: Breast Cancer Facts \& Figures 20152016. Atlanta: American Cancer Society, Inc., 2015.

3 Dhiman TR, Nam SH and Ure AL: Factors affecting conjugated linolecic acid content in milk and meat. Crit Rev Food Sci Nutr 45: 463-482, 2005.

4 Koronowicz AA and Banks P: Anti-tumor properties of CLAenriched food products. Nutr Cancer, 2018. doi:10.1080/ 01635581.2018.1460684. [Epub ahead of print] 
5 Stachowska E, Baśkiewicz-Masiuk M, Dziedziejko V, Gutowska I, Baranowska-Bosiacka I, Marchlewicz M, Dołegowska B, Wiszniewska B, Machaliński B, Chlubek D: Conjugated linoleic acid increases intracellular ROS synthesis and oxygenation of arachidonic acid in macrophages. Nutrition 24(2): 187-199, 2008.

6 Roberfroid MB: Global view on functional foods: European perspectives. Br J Nutr 88(2): 133-138, 2002.

7 Franczyk-Żarów M, Kostogrys RB, Szymczyk B, Jawień J, Gajda M, Cichocki T, Wojnar L, Chlopicki S, Pisulewski PM: Functional effects of eggs, naturally enriched with conjugated linoleic acid, on the blood lipid profile, development of atherosclerosis and composition of atherosclerotic plaque in apolipoprotein $\mathrm{E}$ and low-density lipoprotein receptor doubleknockout mice (ApoE/Ldlr-/-). Br J Nutr 99: 49-58, 2008.

8 Koronowicz AA, Banks P, Domagała D, Master Leszczyńska T, Piasna E, Marynowska M, and Laider P: Fatty acid extract from CLA-enriched egg yolks can mediate transcriptome reprogramming of MCF-7 cancer cells to prevent their growth and proliferation. Genes Nutr 11: 22, 2016.

9 Bouattour MA, Casals R, Albanell E and Caja G: Feeding soybean oil to dairy goats increases conjugated linoleic acid in milk. J Dairy Sci 91(6): 2399-2407, 2008.

10 Koronowicz A, Dulińska-Litewka J and Pisulewski P and Laidler P: Wpływ lipidów żółtka jaja kurzego wzbogaconego w izomery sprzężonego kwasu linolowego na proliferację komórek MCF7. Zywn Nauk Technol J 4(65): 55-61, 2009.

11 Koronowicz A, Żwawa K, Szymczyk B, Pisulewski P and Laidler P: Wpływ lipidów żółtka jaja kurzego naturalnie wzbogaconego w izomery sprzężonego kwasu linolowego na proliferację komórek czerniaka ludzkiego. Bromatol Chem Toksykol XLII(3): 1047-1051, 2009.

12 Koronowicz AA, Banks P, Szymczyk B, Leszczyńska T, Master A, Piasna E, Szczepański W, Domagała D, Kopeć A, Piątkowska E, and Laidler P: Dietary conjugated linoleic acid affects blood parameters, liver morphology and expression of selected hepatic genes in laying hens. Br Poult Sci 57(5): 663-673, 2016.

13 Koronowicz AA, Drozdowska M, Wielgos B, Piasna-Słupecka E, Domagała D, Dulińska-Litewka J and Leszczyńska T: The effect of "NutramilTM Complex", food for special medical purpose, on breast and prostate carcinoma cells. PLoS One 13(2): e0192860, 2018.

14 Arur S, Uche UE, Rezaul K, Fong M, Scranton V, Cowan AE, Mohler W and Han DK: Annexin I is an endogenous ligand that mediates apoptotic cell engulfment. Dev Cell 4(4): 587-598, 2003.

15 Vermes I, Haanen C, Steffens-Nakken H and Reutelingsperger C: A novel assay for apoptosis- flow cytometric detection of phosphatidylserine expression on early apoptotic cells using fluorescein-labeled annexin-V. J Immunol Methods 184(1): 39$51,1995$.

16 Wang XW and Harris CC: P53 tumor-suppressor gene: Clues to molecular carcinogenesis. J Cell Physiol 173(2): 247-255, 1997.

17 Mirzayans R, Andrais B, Scott A and Murray D: New insights into p53 signalling and cancer cell response to DNA damage: Implications for cancer therapy. J Biomed Biotechnol 2012: 170325, 2012.

18 Moll UM and Zaika A: Nuclear and mitochondrial apoptotic pathways of p53. FEBS Lett 493: 65-69, 2001.

19 Nakano K and Vousden KH: PUMA, a novel proapoptotic gene, is induced by p53. Mol Cell 7(3): 683-694, 2001.
20 Tsujimoto Y: Role of BCL-2 family proteins in apoptosis: apoptosomes or mitochondria? Genes Cells 3(11): 697-707, 1998.

21 Villunger A, Michalak EM, Coultas L, Müllauer F, Böck G, Ausserlechner MJ and Adams JM and Strasser A: p53- and drug-induced apoptotic responses mediated by BH3-only proteins PUMA and NOXA. Science 302(5647): 1036-1038, 2003.

22 Hemann MT, Zilfou JT, Zhao Z, Burgess DJ, Hannon GJ and Lowe SW: Suppression of tumorigenesis by the p53 target PUMA. Proc Natl Acad Sci USA 101(25): 9333-9338, 2004.

23 Datta SR, Dudek H, Tao X, Masters S, Fu H, Gatoh Y and Greenberg ME: AKT phosphorylation of BAD couples survival signals to the cell-intrinsic death machinery. Cell 91(2): 231-241, 1997.

24 Fernando R, Foster JS, Bible A, Ström A, Pestell RG, Rao M, Saxton A, Beak SJ, Yamaguchi K, Donnell R, Cekanova M and Wimalasena $\mathrm{J}$ : Breast cancer cell proliferation is inhibited by BAD: regulation of cyclin D1. J Biol Chem 282(39): 2886428873, 2007.

25 Katsogiannou M, Andrieu C, Baylot V, Baudot A, Dusetti NJ, Gayet O, Finetti P, Garrido C, Birnbaum D, Bertucci F, Brun C and Rocchi P: The functional landscape of HSP27 reveals new cellular processes such as DNA repair and alternative splicing and proposes novel anticancer targets. Mol Cell Proteomics 13(12): 3585-3601, 2014

26 Li Y, Lu X, Qi H, Li X, Xiao X and Gao J: Ursolic acid induces apoptosis through mitochondrial intrinsic pathway and suppression of ERK1/2 MAPK in HeLa cells. J Pharmacol Sci 125(2): 202-210, 2014.

27 Vivanco I and Sowyers CL: The phosphatidylinositol 3-kinaseAKT pathway in human cancer. Nat Rev Cancer 2: 489-502, 2002.

28 Riaz A, Zeller KS and Johansson S: Receptor-specific mechanisms regulate phosphorylation of AKT at Ser473: role of RICTOR in $\beta 1$ integrin-mediated cell survival. PLoS One 7(2): e32081, 2012.

29 Kennedy SG, Kandel ES, Cross TK and Hay N: AKT/protein kinase $\mathrm{B}$ inhibits cell death by preventing the release of cytochrome $c$ from mitochondria. Mol Cell Biol 19(8): 5800$5810,1999$.

30 Zhou H, Li XM, Meinkoth J and Pittman RN: AKT regulates cell survival and apoptosis at a postmitochondrial level. J Cell Biol 151(3): 483-494, 2000.

31 Asselin E, Mills GB and Tsang BK: XIAP regulates AKT activity and caspase-3-dependent cleavage during cisplatininduced apoptosis in human ovarian epithelial cancer cells. Cancer Res 61(5): 1862-1868, 2001.

32 Jeong SJ, Dasgupta A, Jung KJ, Um JH, Burke A, Park HU and Brady JN: PI3K/AKT inhibition induces caspase-dependent apoptosis in HTLV-1-transformed cells. Virology 370(2): 264$272,2008$.

33 Kolek O, Gajkowski B, Godlewski MM and Motyl T: Antiproliferative and apoptotic effect of TGF- $\beta 1$ in bovine mammary epithelial BME-UV1 cells. Comp Biochem Physiol C Toxicol Pharmacol 134(4): 417-430, 2003.

34 Gajewska $\mathrm{M}$ and Motyl T: IGF-binding proteins mediate TGFbeta 1-induced apoptosis in bovine mammary epithelial BMEUV1 cells. Comp Biochem Physiol C Toxicol Pharmacol 139(13): $65-75,2004$. 
35 Lei XY, Yao SQ, Zu XY, Huang ZX, Liu LJ, Zhong M, Zhu BY, Tang SS and Liao DF: Apoptosis induced by diallyl disulfide in human breast cancer cell line MCF-7. Acta Pharmacol Sin 29(10): 1233-1239, 2008.

36 Chen CL, Lin CF, Chang WT, Huang WC, Teng CF and Lin YS: Ceramide induces p38 MAPK and JNK activation through a mechanism involving a thioredoxin-interacting protein-mediated pathway. Blood 111(8): 4365-4374, 2008.

37 Herr I and Debatin KM: Cellular stress response and apoptosis in cancer therapy. Blood 98: 2603-2614, 2001.

38 Korwek $\mathrm{Z}$ and Alster O: Rola szlaku indukowanego uszkodzeniami DNA w apoptozie i starzeniu komórkowym. Postepy Biochem 60(2): 248-262, 2014.

39 de Lange J, Verlaan-de Vries M, Teunisse AF and Jochemsen AG: CHK2 mediates RITA-induced apoptosis. Cell Death Differ 19(6): 980-989, 2012.

40 Verma IM, Stevenson JK, Schwarz EM, Van Antwerp D and Miyamoto S: Rel/NF-kB/IkB familv: intimate tales of association and dissociation. Genes Dev 9: 2723-2735, 1995.

41 Okada M, Matsuzawa A,Yoshimura A and Ichijo H: The lysosome rupture-activated TAK1-JNK pathway regulates NLRP3 inflammasome activation. J Biol Chem 289(47): 32926-32936, 2014.

42 Garrido C, Galluzzi L, Brunet M, Puig PE, Didelot C and Kroemer G: Mechanisms of cytochrome $c$ release from mitochondria. Cell Death Differ 13(9): 1423-1433, 2006.

43 van Loo G, Saelens X, van Gurp M, MacFarlane M, Martin SJ and Vandenabeele P: The role of mitochondrial factors in apoptosis: a Russian roulette with more than one bullet. Cell Death Differ 9(10): 1031-1042, 2002.

44 Du C, Fang M, Li Y, Li L and Wang X: SMAC, a mitochondrial protein that promotes cytochrome c-dependent caspase activation by eliminating IAP inhibition. Cell 102(1): 33-42, 2000.

45 Cai J, Yang J and Jones DP: Mitochondrial control of apoptosis: the role of cytochrome c. Biochim Biophys Acta 1366(1-2): 139149, 1998

46 Hill MM, Adrain C, Duriez PJ, Creagh EM and Martin SJ: Analysis of the composition, assembly kinetics and activity of native Apaf-1 apoptosomes. The EMBO J 23(10): 2134-2145, 2004.

47 Budihardjo I, Oliver H, Lutter M, Luo X and Wang X: Biochemical pathways of caspase activation during apoptosis Annu Rev Cell Dev Biol 15: 269-290, 1999.

48 Schägger H: Respiratory chain supercomplexes of mitochondria and bacteria. Biochim Biophys Acta Bioenerg 1555(1-3): 154$159,2002$.
49 Schimmer AD: Inhibitor of apoptosis proteins: Translating basic knowledge into clinical practice. Cancer Res 64(20): 7183-7190, 2004.

50 Jänicke RU: MCF-7 breast carcinoma cells do not express caspase-3. Breast Cancer Res Treat 117(1): 219-221, 2008.

51 Germain M, Affar EB, D'Amours D, Dixit VM, Salvesen GS and Poirier GG: Cleavage of automodified poly(ADP-ribose) polymerase during apoptosis. Evidence for involvement of caspase-7. J Biol Chem 274(40): 28379-28384, 1999.

52 Mc Gee MM, Hyland E, Campiani G, Ramunno A, Nacci V and Zisterer DM: Caspase-3 is not essential for DNA fragmentation in MCF-7 cells during apoptosis induced by the pyrrolo-1,5benzoxazepine, PBOX-6. FEBS Lett 515(1-3): 66-70, 2002.

53 Tor YS, Yazan LS, Foo JB, Armania N, Cheah YK, Abdullah R and Imam MU, Ismail $\mathrm{N}$ and Ismail $\mathrm{M}$ : Induction of apoptosis through oxidative stress-related pathways in MCF-7, human breast cancer cells, by ethyl acetate extract of Dillenia suffruticosa. BMC Complement Altern Med 14(1): 55, 2014.

54 Constantinou C, Papas KA and Constantinou AI: Caspaseindependent pathways of programmed cell death: The unravelling of new targets of cancer therapy? Curr Cancer Drug Targets 9(6): 717-728, 2009.

55 Boulares HA, Yakovlev AG and Smulson ME: Genome degradation by DNAS1L3 endonuclease. In: Poly(ADPRibosyl)ation. Burkle A. Boston, Springer US, pp. 118-131, 2006.

56 Islam MA, Kim YS, Jang WJ, Lee SM, Kim HG, Kim SY, Kim Jo and Ha YL: A Mixture of trans, trans conjugated linoleic acid induces apoptosis in MCF-7 human breast cancer cells with reciprocal expression of BAX and BCL-2. J Agric Food Chem 56(14): 5970-5976, 2008.

57 Kadirareddy RH, Vemuri SG and Palempalli UM: Probiotic conjugated linoleic acid mediated apoptosis in breast cancer cells by downregulation of NF-kB. Asian Pac J Cancer Prev 17(7): 3395-3403, 2016.

58 Fritsche J, Fritsche S, Solomon MB, Mossoba MM, Yurawecz MP, Morehouse K and Ku Y: Quantitative determination of conjugated linoleic acid isomers in beef fat. Eur J Lipid Sci Technol 102(11): 667-672, 2000.
Received March 16, 2018

Revised April 9, 2018

Accepted April 17, 2018 